\title{
Oration
}

\section{Minimizing the risks of twin pregnancy}

\author{
(Extracted from the Professor D. E. Gunatilleke Oration 2018)
}

T Dias ${ }^{\mathrm{a}}$

\section{Introduction}

Currently twin pregnancies account for about $1 \%$ of all pregnancies worldwide. The incidence of natural twin pregnancy usually varies with the maternal age, parity, heredity, individual proneness, nutritional status of the mother, race and the season of conception ${ }^{1,2}$. This variability is mostly attributed to the dizygotic twining rate and it is generally considered that the monozygotic rate is constant ${ }^{3}$. Nigeria has the highest incidence of naturally conceived twin pregnancies and the lowest incidence of twin pregnancies has been reported in Japan, where almost two-thirds of multiple births are identical twins. It is considered that older mothers are more likely to have spontaneous multiple births. However, the increased use of Assisted Reproductive Technologies also increases the rate of twin pregnancies associated with advanced maternal age ${ }^{4-6}$. "Repeat frequency" which is known as the frequency of twinning among women who have already given birth to twins, is significantly higher than in the general population. Even though the individual propensity is not necessarily genetic in origin, pedigree studies have confirmed a family trait in twinning.

Previous studies demonstrate that multiple pregnancies give rise to poor perinatal outcomes compared to singletons ${ }^{7-12}$. Multiple births are associated with elevated risks of maternal complications, including gestational diabetes mellitus and pre-eclampsia preterm delivery, low birth weight, selective fetal growth restriction (sFGR), twin to twin transfusion syndrome (TTTS), placental abruption, post-partum haemorrhage and fetal and infant demise $e^{7-11}$. Frequently, multiple pregnancies also result in caesarean delivery due to a malpresentation of the first twin.

\section{Chorionicity determination}

Chorionicity can be determined using ultrasonography with several markers such as placental number, fetal sex, intertwin membrane thickness and twin peak $\operatorname{sign}^{13}$. Proliferating chorionic villi growing into the potential space between the two layers of amnion in the inter-twin membrane of a dichorionic twin pregnancy produce a $\lambda$-sign, while single chorion of a monochorionic twin pregnancy act as an intact barrier, preventing villi from growing between the two amniotic layers resulting in a $\mathrm{T}$ sign. In a retrospective observational study, Dias et al looked at first-trimester routine ultrasound scan and chorionicity was assigned according to the number of placental masses and $\mathrm{T}$ or $\lambda$-signs for a single placental mass ${ }^{14}$. Chorionicity was confirmed by histology or discordant sex at birth. A total of 648 pregnancies were assigned chorionicity

Sri Lanka Journal of Obstetrics and Gynaecology

2018; 40: 58-62

DOI: http://doi.org/10.4038/sljog.v40i3.7856

aProfessor in Obstetrics and Gynaecology, Faculty of Medicine, University of Kelaniya, Sri Lanka.

Correspondence: TD, e-mail: <thiran_dias@yahoo.com>

http://orcid.org/0000-0002-4931-5607

Competing interest: The author reports no conflict of interest

This is an open-access article distributed under the terms of the Creative Commons Attribution 4.0 International License, which permits unrestricted use, distribution and reproduction in any medium provided the original author and source are credited. 
by first-trimester ultrasound during the study period. Chorionicity was ascertained in 613 cases, either by histology $(n=340)$ or discordant sex $(n=273)$. Chorionicity was correctly assigned by ultrasound at 11-14 weeks in 612 of 613 pregnancies (accuracy $99.8 \%$ ). Sensitivity and specificity for determining monochorionicity were $100 \%$ and $99.8 \%$, respectively. Chorionicity determination was found to be more practicable and accurate at 11-14 weeks' gestation ${ }^{14}$.

\section{Prediction of late complication during first trimester}

It is very useful in the process of management, if the clinicians can predict the late pregnancy complications during first trimester in twin pregnancies. Memmo et al used a total of 242 monochorionic twin pregnancies in their study (102 TTTS, 36 sFGR and 104 controls) ${ }^{15}$. The median CRL discrepancy in the sFGR group $(11.9 \%)$ was significantly higher $(\mathrm{p}<0.001)$ than in the TTTS group (3.8\%) and control group (3.5\%). Median inter-twin nuchal translucency (NT) discrepancies were not significantly different $(\mathrm{p}=0.869)$ between sFGR and both TTTS and control groups (15.6\%, $16.7 \%$ and $14.8 \%$, respectively). Discrepancy in Crown Rump Length (CRL) performed well as a screening test for sFGR (area under ROC curve=0.89), but not for TTTS (area under ROC curve $=0.58$ ). Using a CRL discrepancy threshold of $7.12 \%$ for the prediction of sFGR gave a sensitivity of $92 \%(95 \% \mathrm{CI}$ $78-98 \%)$ and a specificity of 76\% (95\% CI 70-82\% $)^{15}$.

The Southwest Thames Obstetric Research Collaborative (STORK) group evaluated the association between CRL discordance and stillbirth, neonatal mortality, fetal growth restriction, preterm birth at $<34$ weeks' gestation and birth weight and ultrasound estimated fetal weight (EFW) discordance of $\geq 25 \%{ }^{16}$. They concluded that in the absence of aneuploidy or structural fetal anomaly, CRL discordance was a poor predictor for fetal loss at $<24$ weeks (area under the ROC curve (AUC), 0.54 (95\% CI, 0.46-0.62)), perinatal loss (AUC, 0.52 (95\% CI, 0.41-0.64)), BW discordance (AUC, 0.61 (95\% CI, 0.56-0.65)), birth weight $<5^{\text {th }}$ centile $($ AUC, $0.56(95 \%$ CI, 0.530.59)), EFW discordance (AUC, 0.55 (95\% CI, 0.51$0.60)$ ) and preterm birth at $<34$ weeks (AUC, 0.50 $\left(95 \%\right.$ CI, 0.47-0.54)) ${ }^{16}$.

\section{Early pregnancy loss in monochorionic diamniotic (MCDA) and dichorionic diamniotic (DCDA) twins}

There is lack of high-quality data with regard to the survival rates of monochorionic twins at pre-viable gestational ages ${ }^{17}$. STORK group included 3117 twin pregnancies to evaluate early fetal loss in 605 monochorionic (MC) and 2512 dichorionic (DC) twin pregnancies ${ }^{17}$. They have demonstrated that the total risk of early pregnancy loss before 24 weeks was notably higher in MC twins (60.3 per 1000 fetuses) than in DC twins (6.6 per 1000 fetuses). There is a significant difference in survival between $\mathrm{MC}$ and DC twins from 14 to 24 weeks $(\mathrm{p}<0.0001)$ and from 14 to 34 weeks $(\mathrm{p}<0.0001)$. This discrepancy in mortality was a result of the difference in the survival trend in early gestation (14-24 weeks, $\mathrm{p}<0.0001)$, while there was no statistically significant difference from 24 to 34 weeks' gestation $(p=0.08)^{17}$. In this study, they divided the study population in to two time windows consisting of two five year periods of care (year 20002004 and year 2005-2010). Early fetal-loss rates for MC pregnancies from 2005 to 2010 was significantly lower than that from 2000 to 2004. However, this difference was not demonstrated in late fetal losses in $\mathrm{MC}$ and DC. This change in survival was seen after the regional implementation of a program of surveillance for TTTS using ultrasound scans at 17 and 19 weeks and referral for fetoscopic laser therapy in $2002^{17}$.

\section{Influence of chorionicity and gestational age at single fetal loss on risk of preterm birth in twin pregnancy}

Single intrauterine death (sIUD) in twin pregnancy is associated with unfavorable pregnancy outcomes and it may have an intense impact on the surviving twin. Adverse outcomes such as preterm birth, cotwin demise and neurological morbidities of the surviving fetus, have been reported in these pregnancies ${ }^{18}$. Even though these adverse effects are more common in MC twins, they can also occur even in DC twins, in view of the unusual vascular arrangement of placental anastomoses, but the reported incidence is lower in these cases ${ }^{18,19}$. It is considered that gestational age at loss and chorionicity are the two main factors that determine the perinatal outcome in the surviving $\operatorname{cotwin}^{18}$. Although the prevalence of sIUD is higher during the early embryonic period this can occur at any time during pregnancy. The incidence of sIUD was less in DC twins compared with MC twin pregnancy ${ }^{18}$. However, DC pregnancies with sIUD are still at higher risk for unfavorable perinatal outcome compared with uncomplicated DC pregnancies ${ }^{18}$. Preterm birth after sIUD in twin pregnancy may occur from spontaneous preterm labor or iatrogenic delivery because of the obstetricians' concerns about the risk to the cotwin, especially in the case of MC pregnancy. 
A study conducted by STORK group included 3013 twin gestations (2469 DC and $544 \mathrm{MC})^{20}$. The occurrence of preterm birth at $<34$ weeks $<32$ weeks and $<28$ weeks was $66.1 \%, 48.4 \%$ and $19.4 \%$ of twin pregnancies with sIUD respectively. The risk for preterm birth was higher when the sIUD occurred later in gestation, both in $\mathrm{MC}$ and in $\mathrm{DC}$ twin pregnancies. This finding should be interpreted with caution because it might be related to iatrogenic delivery rather than to spontaneous preterm labor induced by the sIUD, although in the STORK centers it was not common clinical practice to expedite delivery in the case of SIUD, except in cases with signs of impending fetal compromise, such as abnormal cardiotocogram (CTG) or fetal Doppler Blood Flow Velocimetry. When compared with DC twins, MC twins affected by sIUD were not at significantly increased risk of preterm birth before either $34(\mathrm{p}=0.626), 32(\mathrm{p}=0.931)$ or $28(\mathrm{p}=0.965)$ weeks of gestation.

\section{Weight discordance and perinatal mortality in twins}

Weight discordance is present in all twin pregnancies and may indicate a physiological condition or an adaptive effect to the intrauterine environment. On the other hand, weight discordance may be the indicator of pathological conditions involving the fetuses or the placenta $^{21}$. Extreme growth discordance in twins, related to an elevated risk of perinatal loss and morbidity ${ }^{22}$. Despite the routine obstetric practice of regular screening in twin pregnancies by ultrasound scans to assess the degree of intertwin fetal growth discordance, there is no consensus as to the optimum cut-off of actual birth weight discordance that can assume an adverse outcome. A retrospective study carried out by STORK group included a total of 2161 twin pregnancies (302 MC and 1859 DC) and they showed that birth weight and/or estimated fetal weight discordance of $\geq 25 \%$ constitute the optimal cut-off for the prediction of stillbirth and neonatal mortality, notwithstanding chorionicity or individual fetal size ${ }^{22}$. Birth weight discordance of $25 \%$ had a detection rate of $47 \%$ for a false-positive rate of $10 \%$ and EFW discordance of $25 \%$ had a detection rate of $42 \%$ for a false-positive rate of $11 \%$. Logistic regression analysis demonstrated that gestational age at delivery (odds ratio (OR) 0.75 (95\% CI, 0.69-0.81); p<0.0001) and BW discordance (OR 1.07 (95\% CI, 1.05-1.09); $<<0.0001$ ) were independent predictors of perinatal loss, while chorionicity, either twin having a birth weight $<5$ th percentile and maternal age were not $(\mathrm{p}=0.193,0.678$ and 0.767 , respectively). A policy of frequent fetal surveillance starting from 26 weeks' gestation and elective delivery by 38 weeks of gestation might be appropriate for pregnancies above this cut-off ${ }^{22}$.

\section{Timing of birth in twin pregnancy}

There are ongoing discussions on the ideal timing for birth in otherwise uncomplicated MC twins. Clinical opinion is equally divided between late preterm elective delivery to avoid late stillbirth ${ }^{23-26}$ and expectant management as for DC twins. However, MC twins are routinely delivered electively at late preterm gestation with the aim of avoiding stillbirth at term ${ }^{27}$. A retrospective study carried out by STORK group consisted of 3005 twin pregnancies delivered after 26 weeks' gestation. The total risk of stillbirth after 26 weeks in MC twins was approximately three times higher than in DC twins and did not change significantly between 26 weeks and 36 weeks of gestation in MC twins ${ }^{27}$. This study demonstrated that there was no significant elevation of the still birth rate near term in MC twins and the authors postulated that this could have been due to the policy of regular surveillance and elective delivery from 36 weeks ${ }^{27}$. However, their data did not reinforce a policy of elective delivery before 36 weeks' gestation in $\mathrm{MC}$ twin pregnancies.

Dias et al. demonstrated that the risk of stillbirth in dichorionic twins after 26 weeks remained static $^{28}$. Recent studies suggest that the stillbirth rate in DC twins is constant after 26 weeks but only up to 38-39 weeks of gestation. The rates of fetal death appear to increase significantly once a gestational age of 38-39 weeks is reached ${ }^{29}$. Therefore, it is reasonable to have expectant management until 38 weeks and then plan elective delivery at 38 weeks in uncomplicated DC twin pregnancies. However, if the woman intends to prolong the pregnancy beyond 38 weeks, then fetal growth and wellbeing should be assessed thoroughly. If FGR is detected, then delivery should be arranged, but even in the presence of reassuring assessment of fetal wellbeing, unfavorable outcomes may still be a risk, beyond this gestation ${ }^{30}$.

Neonatal morbidity with increasing gestation of twins has not been assessed much. In a retrospective study Hack et al. reported that $80 \%$ of MC twins and $66 \%$ of DC twins were admitted to the neonatal unit ${ }^{24}$. The number of twins admitted to the neonatal intensive care unit was also elevated in MC twins than in DC twins (29.4 and $19.5 \%$, respectively).

\section{Conclusion}

Currently twin pregnancies account for about $1 \%$ of all pregnancies worldwide. Previous studies demon- 
strate that multiple pregnancies give rise to poor perinatal outcomes compared with singletons. Chorionicity can be determined using ultrasonography with several markers such as placental number, fetal sex, intertwin membrane thickness and twin peak sign. Chorionicity determination is more practicable and accurate at 11-14 weeks' gestation. Prediction of late complications during first trimester is very useful in the process of management. ISUOG has recently recommended that the management of twin pregnancy with CRL discordance $\geq 10 \%$ or of NT discordance $\geq 20 \%$ should be discussed with a Fetal Medicine expert. $\mathrm{MC}$ twins are variably reported to be at two to fivefold increased risk of perinatal mortality and morbidity compared with dichorionic DC Twins. The chorionicityrelated mortality is thought to be a consequence of either vascular sharing or placental sharing in $\mathrm{MC}$ twin pregnancy. sIUD in twin pregnancy is related with adverse outcomes such as preterm birth, cotwin demise and neurological morbidities of the surviving fetus, and these effects are more common in MC twins. It is considered that gestational age at loss and chorionicity are the two main factors that determine the perinatal outcome in the surviving cotwin. Weight discordance is present in all twin pregnancies and may indicate a physiological condition or an adaptive effect to the intrauterine environment. This can be an indicator of pathological conditions involving the fetuses or the placenta. Extreme growth discordance in twins, related to an elevated risk of perinatal loss and morbidity. There are ongoing discussions about an ideal timing of birth in otherwise uncomplicated MC twins. Clinical fraternity is uniformly divided between elective late preterm delivery to avoid late stillbirth and expectant management for DC twins. Monochorionic twins are routinely delivered electively at late preterm gestation with the aim of avoiding stillbirth at term. Recent studies suggest that the stillbirth rate in dichorionic twins is constant after 26 weeks but only up until 38-39 weeks of gestation, according to the evidence the rates of fetal death significantly increase once a gestational age of 38-39 weeks is reached.

\section{References}

1. Nylander PPS. Factors which influence twinning rates. In: MacGillivray I, Nylander PPS, Comey G, eds. Human Multiple Reproduction. London: W.B. Saunders, 1975.

2. Allen G, Schachter J. Ease of conception in mothers of twins. Soc Biol. 1971; 18: 18-27.

3. Pritchard J, McDonald P, Gant N. Williams obstetrics, 17th edn., Norwalk, CT: Appleton Century Croffts, United States, 1985; 503-524.

4. Reynolds MA, Shieve LA, Martin JA, et al. Trends in multiple births conceived using assisted reproductive technology, United States, 19972000. Pediatrics 2003;111:1159-62

5. Jewell SE, Yip R. Increasing trends in plural births in the United States. Obstet Gynecol 1995; 85: 229-32

6. Misra DP, Ananth CV. Infant mortality among singletons and twins in the United States during 2 decades: effects of maternal age. Pediatrics 2002; 110: $1163-8$

7. National Center for Health Statistics. 1995-1998 Matched Multiple Birth Data Set. CD-ROM Series 21, No 13a. Hyattsville, MD: Public Health Service, United States, January 2003.

8. National Center for Health Statistics. 1998 Birth Cohort Linked Birth/Infant Death Data Set. CDROM Series 20, No 16a. Hyattsville, MD: Public Health Service, United States, October 2002.

9. Polin JI, Frangipane WL. Current concepts in management of obstetric problems for pediatricians. II. Modern concepts in the management of multiple gestations. Pediatr Clin North Am 1986; 33: 649-61.

10. Gadow EC, Castilla EE, Lopez-Camelo J, Queenan JT. Stillbirth rate and associated risk factors among 869750 Latin American hospital births 19821986. Int J Gynaecol Obstet 1991; 35: 209-14.

11. Luke B. Reducing fetal deaths in multiple births: optimal birth weights and gestational ages for infants of twin and triplet births. Acta Genet Med Gemellol Roma 1996; 45: 333-48.

12. Alexander GR, Kogan M, Martin J, Papiernik E. What are the fetal growth patterns of singletons, twins, and triplets in the United States? Clin Obstet Gynecol 1998; 41: 115-25.

13. Scardo JA, Ellings JM, Newman RB. Prospective determination of chorionicity, amnionicity and zygosity in twin gestations. Am J Obstet Gynecol 1995; 173: 1376-1380.

14. Dias T, Arcangeli T, Bhide A, Napolitano R, MahsudDornan S, Thilaganathan B. First-trimester ultrasound determination of chorionicity in twin pregnancy. Ultrasound Obstet Gynecol 2011; 38: 530-532.

15. Memmo A, Dias T, Mahsud-Dornan S, Papageorghiou A, Bhide A, Thilaganathan B. 
Prediction of selective fetal growth restriction and twin-to-twin transfusion syndrome in monochorionic twins. BJOG 2012;119:417-421.

16. D'Antonio F, Khalil A, Dias T and Thilaganathan B. on behalf of the Southwest Thames Obstetric Research Collaborative (STORK); Crown-rump length discordance and adverse perinatal outcome in twins: analysis of the Southwest Thames Obstetric Research Collaborative (STORK) multiple pregnancy cohort; Ultrasound Obstet Gynecol 2013; 41: 621-626.

17. D'Antonio F, Khalil A, Dias T and Thilaganathan B. on behalf of the Southwest Thames Obstetric Research Collaborative (STORK); Early fetal loss in monochorionic and dichorionic twin pregnancies: analysis of the Southwest Thames Obstetric Research Collaborative (STORK) multiple pregnancy cohort; Ultrasound Obstet Gynecol 2013; 41: 632-636.

18. Hillman SC, Morris RK, Kilby MD. Co-twin prognosis after single fetal death: a systematic review and meta-analysis. Obstet Gynecol 2011; 118: 928-940.

19. Ong SS, Zamora J, Khan KS, Kilby MD. Prognosis for the cotwin following single-twin death: a systematic review. BJOG 2006; 113: 992-998.

20. D'Antonio F, Thilaganathan B, Dias T and Khalil A, on behalf of the Southwest Thames Obstetric Research Collaborative (STORK); Influence of chorionicity and gestational age at single fetal loss on risk of preterm birth in twin pregnancy: analysis of STORK multiple pregnancy cohort; Ultrasound Obstet Gynecol 2017; 50: 723-727.

21. Blickstein I, Kalish RB. Birthweight discordance in multiple pregnancy. Twin Res 2003; 6: 526-531.

22. D'Antonio F, Khalil A, Dias T and Thilaganathan B. on behalf of the Southwest Thames Obstetric Research Collaborative (STORK); Weight discordance and perinatal mortality in twins: analysis of the Southwest Thames Obstetric Research Collaborative (STORK) multiple pregnancy cohort; Ultrasound Obstet Gynecol 2013; 41: 643-648.

23. Hack KE, Derks JB, Elias SG, Franx A, Roos EJ, Voerman SK, Bode CL, Koopman-Esseboom C, Visser GH. Increased perinatal mortality and morbidity in monochorionic versus dichorionic twin pregnancies: clinical implications of a large Dutch cohort study. BJOG 2008; 115: 58-67.

24. Tul N, Verdenik I, Novak Z, Srsen TP, Blickstein I. Prospective risk of stillbirth in monochorionicdiamniotic twin gestations: a population-based study. J PerinatMed 2011; 39: 51-54.

25. Barigye O, Pasquini L, Galea P, Chambers H, Chappell L, Fisk NM (2005) High Risk of Unexpected Late Fetal Death in Monochorionic Twins Despite Intensive Ultrasound Surveillance: A Cohort Study. PLoS Med 2(6): e172. https:// doi.org/10.1371/journal.pmed.0020172.

26. Lee YM, Wylie BJ, Simpson LL, D'Alton ME. Twin chorionicity and the risk of stillbirth. Am J Obstet Gynecol 2008; 111: 301-308.

27. Southwest Thames Obstetric Research Collaborative (STORK); Prospective risk of late stillbirth in monochorionic twins: a regional cohort study; Ultrasound Obstet Gynecol 2012; 39: 500-504.

28. Dias T, Patel D, Bhide A, et al. Prospective risk of late stillbirth in monochorionic twins: a regional cohort study. Southwest Thames Obstetric Research Collaborative (STORK). Ultrasound Obstet Gynecol 2012; 39: 500-4.

29. Kahn B, Lumey LH, Zybert PA, et al. Prospective risk of fetal death in singleton, twin, and triplet gestations: implications for practice. Obstet Gynecol 2003; 102: 685-92.

30. Dias T, Akolekar R, Timing of birth in multiple pregnancy; Best Practice \& Research Clinical Obstetrics and Gynaecology 2014; 28: 319-326. 